\title{
The Thinking of Higher Mathematics Model in Higher Vocational Colleges
}

\author{
Zhu Huaihong ${ }^{1, a}$ \\ ${ }^{1}$ Nanchang Institute of Science and Technology, Nanchang 330108, China \\ azhuhuaihong@126.com
}

Keywords: Higher vocational, Mathematics teaching, Mathematical experiment

\begin{abstract}
Higher mathematics is an essential basic course in Higher Vocational education. In order to achieve better accomplish the teaching of Higher Mathematics in the "necessary and sufficient" under the principle of task, teachers should make new "period" of higher mathematics teaching; to focus on the methods of basic mathematics thought in higher mathematics students' understanding; through the students' practical ability and creative spirit of mathematical experiment and mathematical modeling to enhance the development and utilization of curriculum resources, constantly, to improve their teaching level.
\end{abstract}

\section{The Position of Higher Mathematics in Higher Vocational Education.}

The higher occupation education (hereinafter referred to as the higher vocational education) is an important part of higher education, is to cultivate a certain theoretical knowledge and practical ability, grass roots oriented, production, service and management for first-line occupation practical and technical talents for the occupation technology education. The higher stage, occupation technology education. Higher mathematics is an essential basic course in Higher Vocational education. On the one hand, it paves the way for students to learn the following courses, on the other hand, it is of great significance to the cultivation of students' scientific thinking. Therefore, it is not only an important public compulsory course, but also an important basic course. Under the premise of "necessary and sufficient", it is not only the improvement of knowledge and skills, but also the ability to survive, develop and improve the task of higher mathematics teaching. In view of this situation, the following is the author of higher mathematics teaching.

Our personnel training positions, decide they don't have the calculation formula of the mathematical theorem, the sequence of events like the students majoring in mathematics as to make it clear, but to be able to use these theorems and formulas to solve practical computing problems. Therefore, in the classroom teaching, unnecessary, spend more time to the theoretical derivation, the formula is as far as possible deletion.

For example, four arithmetic operations on the guide, I in the classroom only derived the derivation function product, derivation of the sum and difference, taking no longer is one. However, the necessary condition of function extreme value, the monotonicity theorem of function, and not the strict mathematical proof, as long as the geometric figure is given, and the explanation is given, the students can accept it. The author thinks that it will be better and more effective to use the formula to make more practice and solve the specific problems by using the formula.

Mathematics, especially advanced mathematics, has always been known for its abstract, rigorous, and the opportunity to learn advanced mathematics are not ordinary people, is the elite". The higher vocational education makes this kind of "elite education" into "mass education"'. Therefore, the teaching of Higher Mathematics in higher vocational colleges, is not how high the level of teachers, the mathematical formula, the argument is perfect, it is important for students to learn what, whether it will be applied. What the teacher wants to do is to abstract, complex theory of visualization, visualization, simple, easy to accept students.

For example, in explaining the concept of definite integral, can ask "why do we usually see is the ground plane?" in fact, this is to "straight lines" on the surface, small part can be considered as a plane curve, a very small can also be considered to be straight. This gives students a specific space 
for imagination, so that they know how to use this mathematical theory to explain the phenomenon of life. In this way, not only deepen the understanding of the concept of students, but also conducive to cultivate their interest in learning mathematics.

\section{Some Thoughts on Higher Mathematics Teaching in Higher Vocational Colleges. Do a Good Job in the "run in period".}

"Well begun is half done". From the middle school has just entered the University, because the living environment, learning characteristics, interpersonal relationship and other factors change, many students showed to have different degrees of psychological problems, which belongs to the freshmen's psychological "period", it is inevitable. In the "running in period" of the University, the prominent contradiction is that the bad learning habit caused by the exam oriented education makes the students unable to adapt to the teaching of the university. There is no middle school teacher in the face of many freshmen constantly give personal advice, the knowledge of the ocean, I do not know from He Xueqi, will inevitably have a confused and disoriented feeling. Higher mathematics is the elementary mathematics is very different, the concept of examples in higher mathematics is carefully chosen, is towards the established direction step by step to the solution of the problem, the study should have a strong sense of purpose, the problem is more profound and complicated, the concept is more abstract, there must be thinking clear direction. Elementary mathematics research object basically is invariant, while the higher mathematics is as variable as the research object, the elementary function is a link between elementary mathematics and higher mathematics, limit is an important thinking method to study the function of higher mathematics, so that students learn the first chapter "function and limit" is the new "period" mathematics teaching work key where.

In the first chapter "function and limit" in the teaching process, the function of teaching, some teachers think that students learned in high school, in order to reduce the class in teaching is often less. However, most of the higher vocational students of middle school mathematics knowledge is not solid, but this approach was not still not, it will seriously dampen the enthusiasm of students in mathematics learning. On the limit of teaching, teaching in middle school with the definition of limit limit definition of the same, did not give a strict definition of limit of function, only gives the intuitive description, if teachers in the teaching of the definition of limit, without the necessary groundwork and expansion, is bound to affect the ultimate understanding of the concept, cause students to learn further knowledge obstacles.

How to do the first chapter "function and limit" teaching, and rebuild their confidence to learn mathematics, psychologically to retain students, I think, first, teachers should properly slow down the progress of teaching, help students sort out the function of knowledge, the existing knowledge and methods of organizing, to form a reasonable knowledge structure, and how to learn higher mathematics in the study, methods and strategies for the necessary guidance, "delegate to fish, as delegate to fish", to increase students' confidence in mathematics learning of higher mathematics, closer to the psychological distance with the students. Secondly, the higher mathematics is many elementary mathematics question answers elementary mathematics knowledge in higher mathematics is a special case.

For example: the use of the infinite geometric series and will shrink into circulating decimal fraction, teachers can use these knowledge teaching, improve students' interest in learning. Third, the concept and the concept of limit in Higher Mathematics occupies an important position. Many problems limit is also research tools, these problems involve from the limited understanding of infinite, understanding process accurate, quantitative change to qualitative change from the approximation. Therefore, teachers should make students aware of the improvement of the students' knowledge under the premise of limited knowledge. Teachers can be combined with specific examples, by comparing numerical changes and image interpretation of "infinite approach", and "e -N language" and "epsilon delta language" introduced to students, the focus of teaching is to let students understand the basic concepts and basic ideas, grasp the basic operation of the limit.

Pay attention to the students' understanding of the basic mathematical thinking methods of higher mathematics, cultivate students' ability of sustainable development and lifelong learning 
ability. Think of the new concept of modern occupation education, occupation education project not narrowly corresponds to a specific job design, should cultivate students' corresponding culture theory and knowledge migration ability, can adapt to a variety of job occupation group required knowledge, ability and quality based. Therefore, vocational education should not only attach importance to practical ability, but also attach importance to the study of basic theory.

Mathematics thinking method is the soul of mathematics, it is mathematics from the specific content of mathematics and mathematical understanding view refined rising, the repeated application of mathematics cognition activities, with universal significance, is the guiding ideology to solve problems in mathematics. For example, many ideas and methods in calculus formation for students in the way of thinking and thinking ability training plays a very important role, regardless of the future of students after graduation engaged in what work, mathematics thinking method of calculus is indispensable. In the teaching, should contain mathematical thought and method to fully explore and reveal the textbooks, such as micro element method, reduction method, limit method, replacing curve by straight line method, and guide students to apply these ideas as a thinking tool applied to professional knowledge and other disciplines, and in later professional course of study consciously use mathematical methods to think, in the view of mathematics to thinking. For example, the software of professional students, teachers referred to in the first derivative, but focuses on the first derivative of the $C$ programming language "iterative method" in the application, and thus enable students to understand: for the most important is to cultivate professional software programming ability, the core should be programming ideas, that is mathematics thought is the key to solve the problem, the computer language is to build the core tool.

\section{Mathematical Experiment is an Effective Way to Improve Students' Ability.}

The era of knowledge economy, mathematics is from behind the stage, a combination of mathematics and computer technology can make the mathematics in many aspects directly create value for the society at the same time, also open up broad prospects for the development of mathematics. The extensive application of modern information technology has a profound impact on the content of mathematics curriculum, mathematics teaching, mathematics learning and so on. In 1995, the National Mathematics higher education in the course of the reform of the teaching content curriculum system in the year of twenty-first Century, "mathematics experiment" as one of the basic courses of mathematics. Mathematical experiment is the use of mathematical software to use mathematical methods to learn mathematical knowledge and solve mathematical problems in mathematics teaching.

The establishment of mathematical experiment course, first of all, is to change the teaching mode of the mathematics curriculum, which only rely on "a pen, a piece of paper", and transfer knowledge by the teacher. Mathematical experiment is to point to the students to do the main, under the guidance of teachers with the knowledge of mathematics and computer technology, the choice of appropriate mathematical software, analysis, to solve some of the practical problems. The mathematics experiment will cause a strong interest in learning mathematics knowledge and methods and inspire them to solve practical problems related to the desire, so the mathematics experiment helps to cultivate and promote independent thinking and innovation consciousness.

Secondly, the mathematical experiment is to start from the practical problems, complete the process of learning mathematics, mathematics, mathematics. Not only the results of the experiment is derived, and the formulas apply manual calculation results, it also reflects on the students' mathematical principle, method, mathematical modeling method, computer operation and software used in many aspects such as the master degree and application ability. Therefore, mathematical experiments can help to promote the practical application of the comprehensive application ability training.

Third, it is necessary to use the computer and application software to introduce advanced technology tools into the teaching process. It is not only a teaching aid, but also the main way to solve the problems in the experiment. Therefore, mathematical experiment is helpful to promote the modernization of mathematics teaching methods and to enable students to master advanced 
mathematics tools.

In addition, the mathematics experiment using computer as a tool, the function of powerful mathematical package to solve mathematical problems become convenient, which not only greatly enhance and expand the way of using higher mathematics to solve mathematical problems, but also greatly reduce the computational burden of people using traditional methods, improve the students' interest in learning mathematics and confidence.

\section{Carry out Mathematical Modeling Activities to Improve Students' Practical Ability and Innovative Spirit.}

When people solve some practical problems in economic and social life, need to be studied with the inherent law of language and methods of mathematical expressions, and then the mathematical problem is analyzed and calculated, and the number of the obtained results back to the actual object problems, such a process called in order to establish the mathematical model, referred to as mathematical modeling. The famous British mathematician and philosopher Whitehead (1861 1947) predicted: "if civilization continues to advance in the next two thousand years, the overwhelming novelty in the field of human thoughts, is the dominant of mathematical understanding." The so-called mathematical understanding of the problem, refers to the use of simple language to solve the actual problem into a mathematical model, and then describe the mathematical model can be quantitative or qualitative solution to the problem of 2 .

To carry out the "mathematical modeling" learning activities, the establishment of a mathematical application of the thematic activities, enabling students to experience the role of mathematics in solving practical problems, mathematics and daily life and other disciplines. For example, to put a chair on the uneven ground, usually only three feet on the ground, unstable, but only a few moves a few times, you can make the four feet at the same time, put the stability of the [3]. This phenomenon, which seems to have nothing to do with mathematics, can be expressed in mathematical language, and can be proved by the continuity of a function. Students are strongly interested in this kind of practical background, especially in mathematics problems which are directly related to a practical problem. Mathematical modeling is based on the real object representation of information -- the establishment of mathematical model, the mathematical model, explain the real problem, the whole process of the verification results such as setting up the mathematical model, and to promote the students to gradually form and develop mathematics application consciousness, improve the practice ability.

In recent years, the practice of our college mathematical modeling has fully proved that the development of the application of mathematics teaching activities to meet the needs of society, to stimulate the students' interest in learning mathematics, is conducive to enhancing the students awareness of the application, can expand the horizons of students.

\section{Using mathematical Tools and Mathematical Experiments to Assist Teaching}

Traditional mathematics teaching attaches great importance to the cultivation of students' ability of calculation and operation. For the application of highly skilled personnel, we after employment will not require them to use strict logic to prove a pure mathematical problem or formula. Mathematics is a tool for them to engage in professional work, the main purpose of learning mathematics is to solve the specific problems in the work. Used to change the past neglected the various tables, calculators and other tools in teaching. Because of our talent work in the future if you encounter a math problem, results can be obtained through the tables, calculator, computer and other tools to rapidly and accurately, to achieve the aim of accomplishing a task.

In view of the wide application of computer and mathematical software is becoming more perfect, in order to improve awareness and ability to use computers to solve mathematical problems of the students, we will try the teaching of higher mathematics and computer function combination. In mathematics teaching to open a number of experiments, the introduction of Mathematic, Matlab, geometric drawing mathematical software, derivative, integral, differential equation, the function is 
expanded in power series such as complex operations in computer, drawing the space curved surface and Fourier series by using demonstration software generation and series and approximation the function, introduced and experimental mathematics training of least squares method, have achieved satisfactory results. Through the mathematical experiment, not only can give students a new feeling, stimulate their interest in learning mathematics, to deepen the understanding of the knowledge, but also to the students of the status quo and the development of mathematics has a profound experience.

\section{References}

[1] Y.X.Zhu. Teachers of Higher Vocational M. Shanghai: Shanghai Jiao Tong University press, 2004:1. (In Chinese)

[2] S.Y.Li and L.Guo. Exploration of mathematical experiment curriculum model in Higher Vocational College [J]. Journal of Huaihua University, 2006, (2): 158(In Chinese)

[3] Q.Y.Jiang. Mathematical modeling of M. Beijing: Higher Education Press, 1993:9.(In Chinese)

[4] Z.X. Wang. Theory of problem solving in mathematical methodology (Second Edition) [M]. Changsha: Central South University press, 2002. (In Chinese)

[5] M.Z. Zhou. The practice of higher vocational mathematics reform [J]. mechanical vocational education, 2001, (2). (In Chinese)

[6] J.W. Wang. Research on the reform of mathematics curriculum in Higher Vocational Education[J]. Journal of educational research, 2004, (12). (In Chinese) 